\title{
DISCUSSION
}

\section{Field studies of an instrumented model pile in clay}

\author{
M. R. COOP and C. P. WROTH (1989). Géotechnique 39, No. 4, 679-696.
}

\section{A. J. Bond, Geotechnical Consulting Group, Lon- don, and R. J. Jardine, Imperial College, London}

The authors present results from a series of field experiments with an instrumented model pile (IMP) installed in the Gault Clay at Madingley and in soft silty clays at Huntspill. The data from Madingley is particularly valuable, since there is currently a dearth of reliable information from high quality instrumented pile tests in stiff, heavily over-consolidated clays. We have also been active in this area, although to date our tests have concentrated on observing pile behaviour in stiff, heavily overconsolidated London Clay. A comparison of our results with those of the Authors reveals many areas of agreement, but also some interesting points of disagreement. Our experiments are described by Jardine \& Bond (1989), and in more detail by Bond (1989).

One of the most important findings to arise from our experiments was the observation that the earth and pore water pressures developed at any fixed soil horizon depend strongly on the height $h$ of that horizon above the pile tip. This discovery was made possible by mounting at least three, and in one case five, levels of instrumentation along the pile shaft. The spread of instruments revealed a systematic variation in the radial total stress $\sigma_{\mathrm{r}}$ and pore pressure $u$ with $h / R$ at each soil horizon where $R$ is the pile's radius. There were steep gradients in stress over the length of the pile when it was fully installed. Some of these features can also be seen in the Authors' results. However, our data suggests that the radial effective stress $\sigma_{r}^{\prime}$ depends markedly on $h / R$, whereas this was less apparent in the Authors' experiments.

This ' $h / R$ effect' arises from the highly complicated two-dimensional nature of pile installation. It is not surprising, therefore, that the onedimensional cavity expansion method 'does not accurately model the installation process'. To emphasize this point, Fig. 15 shows the equilibrium radial effective stresses $\sigma_{\mathrm{rc}}{ }^{\prime}$ that were measured in our experiments $36 \mathrm{~h}$ after pile installation in London Clay. The cylindrical cavity expansion method evidently overpredicts the value of $\sigma_{\mathrm{rc}}{ }^{\prime}$ over most of the pile length. Interestingly, the original horizontal effective stress in the ground $\sigma_{\mathrm{ho}}{ }^{\prime}$ appears to form the lower bound value for $\sigma_{\mathrm{rc}}{ }^{\prime}$ as the distance from the pile tip increases. In our experiments the normalized distance between the leading and trailing instruments was approximately $2 \frac{1}{2}$ times that in the Authors' experiments. This allows the stress gradients on the pile shaft to be identified more clearly.

The Authors' pore pressure readings appear to show $u$ varying between -80 and $+350 \mathrm{kPa}$ (see Fig. 5). The negative values are worthy of attention, since they indicate that the Gault Clay is dilating strongly during pile installation (at least close to the pile wall). It is extremely difficult to obtain reliable measurements of pore pressure under these conditions, since the fluid inside the piezometer inevitably cavitates at pressures below about $-80 \mathrm{kPa}$ gauge. This can render the piezometer inactive for a long period afterwards - see, for example, the smooth trace that extends from around $2.5 \mathrm{~m}$ to around $5 \mathrm{~m}$ depth on Fig. 5.

In our experiments, negative pore pressures were recorded during installation along the entire length of the pile. Several versions of piezometer were tried before reliable pore pressure readings were obtained. The instruments incorporated the same semiconductor transducer as was used by the Authors (the Druck PDCR-81), but with important differences in the detailed design of the piezometer (e.g. the cell shape, porous filter and saturating fluid were all different, as were the saturating procedures). We found that when the piezometers were saturated with silicone fluid they recovered almost instantaneously from the effects of cavitation, whereas with water they took many minutes, and sometimes hours, to revive. Details of the instrumentation used in our experiments are given by Bond \& Jardine (1989).

We agree with the Authors that in clays a reoriented shear surface is formed at or near the pile shaft during installation. In addition, our experiments show that the texture of this surface and the ratios of $\tau / \sigma_{\mathrm{r}}{ }^{\prime}$ that can be mobilized on it can be strongly dependent on the rate of pile installation (although $\tau / \sigma_{r}{ }^{\prime}$ appears to be independent of $h / R$ ).

Figure 16 illustrates this rate effect in terms of the average $\alpha$ values $\left(\alpha=\bar{\tau} / \bar{c}_{\mathrm{u}}\right)$ recorded during pile installation at a single London Clay site 


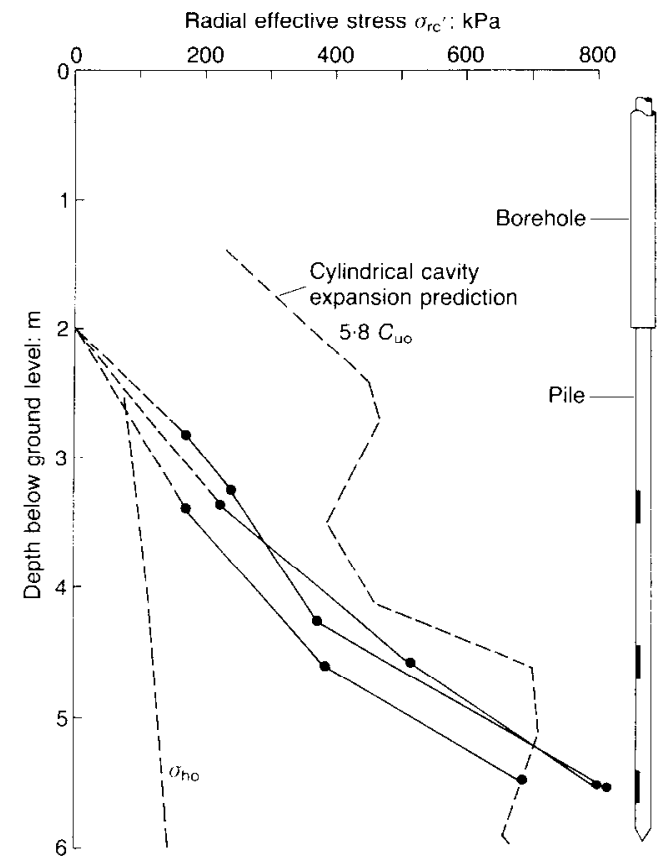

Fig. 15. Radial effective stresses measured $36 \mathrm{~h}$ after pile installation in London Clay (Bond, 1989)

(Canons Park). The rate effect is indeed small over the range of velocities considered by the Authors, but there is a dramatic rise in $\alpha$ (from around 0.5 to around 0.9 ) as the installation rate increases from 100 to $500 \mathrm{~mm} / \mathrm{min}$. The observed jump in skin friction matches the behaviour of the London Clay in interface ring-shear tests over the same range of velocities (Jardine \& Lemos, 1989).

The pile's capacity in subsequent slow loading tests also depends on the rate of installation, but the variation is not as marked as that described above. (The capacity increases by around $70 \%$ as the velocity increases from 100 to $500 \mathrm{~mm} / \mathrm{min}$.) This implies that the jump in $\alpha$ revealed by Fig. 16 is not solely a viscous effect, but is also related to changes in the shearing mechanism in the soil. Measurements of peak $\tau / \sigma_{\mathrm{r}}{ }^{\prime}$ in subsequent slow loading tests confirm this interpretation. Correlations between the field tests and laboratory experiments reported by Lemos (1986) and Tika (1989) show that the effects of fast shearing on subsequent slow loading can be predicted by interface ring-shear tests (Jardine \& Lemos, 1989).

In conclusion, the Authors' experiments make an important contribution to the admittedly sparse database of high quality field tests with instrumental piles. Synthesis of the Authors' data with the results of similar experiments recently completed by the Norwegian Geotechnical Institute, British Petroleum and Imperial College may provide the opportunity for significant improvements to be made to the current (empirical) design rules for displacement piles in clays.

\section{Authors' reply}

We agree that the measurement of large negative pore pressures does require transducers to be saturated with a fluid other than water, but we would emphasize that the overwhelming majority of pore pressure measurements shown on Fig. 5 are positive and only one, or possibly two, of the 25 traces shown appear to have been influenced by cavitation. This is not, therefore, a significant factor affecting the reliability of the data.

Model pile tests have also been conducted by the Authors at Canons Park, and some of the data are presented in Fig. 17. Although the data are much less extensive than those gathered at Madingley, they provide a useful comparison with Bond \& Jardine's data. As at Madingley the cavity expansion predictions appear to give a useful estimate of the effective radial stress $\sigma_{r}^{\prime}$ during installation, although at Canons Park the predictions form a lower bound to measurements. As at Madingley, however, radial total stresses and pore pressures were significantly lower than cavity expansion prediction so that, as Bond \& Jardine have found, the increase in $\sigma_{\mathrm{r}}{ }^{\prime}$ during reconsolidation predicted by cavity expansion does not occur.

We believe that the investigation of a possible rate effect on shaft friction requires a more rigorous treatment than that given in Fig. 16, as the

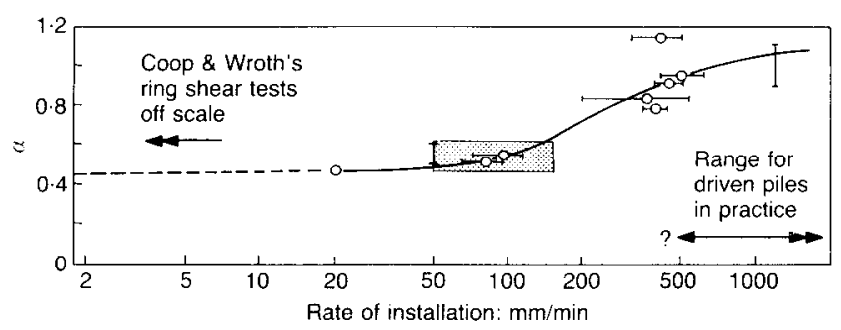

Fig. 16. Rate effect observed during pile installation in London Clay in terms of $\alpha$ : closed-ended jacked piles, some instrumented (Bond, 1989) 


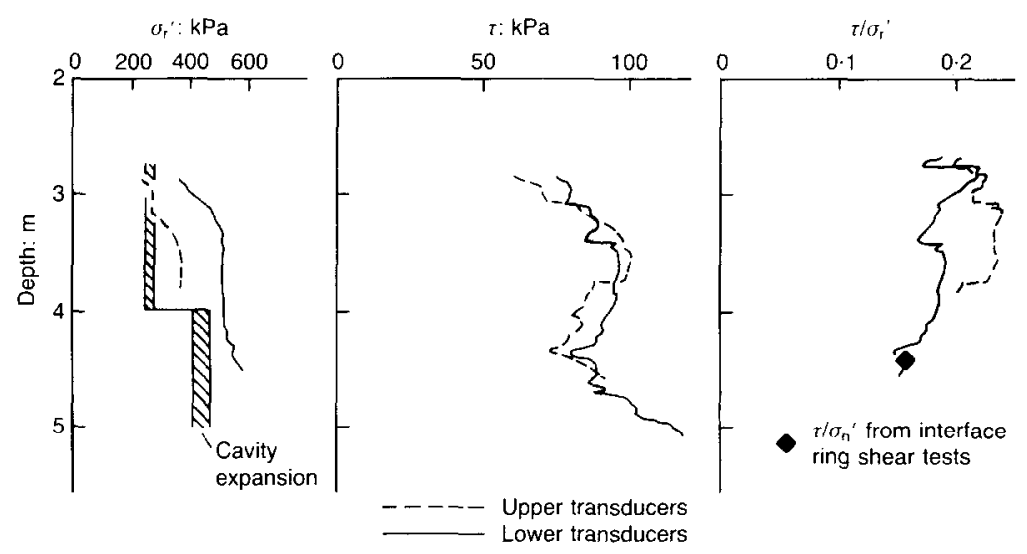

Fig. 17. IMP data from Canons Park

normalization of shaft friction with respect to the initial undrained shear strength of the soil does not allow for any changes in the shear strength, which itself may be affected by rate effects on the mobilized friction angle or by changes in the effective stress. We have investigated the former by conducting two ring shear tests on brass interfaces, using the procedures outlined in the Paper. The samples were retrieved by the IMP from a depth of $4.4 \mathrm{~m}$, and as shown in Fig. 18 the value of $\tau / \sigma_{n}{ }^{\prime}$ or 0.0157 for the slow drained ring shear tests agreed very closely at this depth with the $\tau / \sigma_{r}{ }^{\prime}$ data from the IMP installation, which at this site was conducted at a rate varying from 220 $540 \mathrm{~mm} / \mathrm{min}$. Although the excellent agreement of the data may to some extent be fortuitous, any influence of rate of shearing on the mobilized friction angle appears much smaller than that proposed by Bond $\&$ Jardine.

Bond \& Jardine suggest that we had not investigated a sufficient range of velocities to observe a rate effect. Fig. 18 amplifies the point in the Paper that in fact for the Madingley site a range of velocities was investigated from $0.02 \mathrm{~mm} / \mathrm{min}$ to $1300 \mathrm{~mm} / \mathrm{min}$, a considerably greater range than for the data given on Fig. 16. Our interface ring shear data are shown on Fig. 18 along with the range of $\tau / \sigma_{\mathrm{r}}{ }^{\prime}$ values for the IMP during installation from Fig. 5. While the nominal penetration rate for the IMP field tests was $200 \mathrm{~mm} / \mathrm{min}$, a closer examination of the Madingley data has revealed an average rate of $300 \mathrm{~mm} / \mathrm{min}$ for the five boreholes presented in the Paper. Also shown on Fig. 18 are the values of $\tau / \sigma_{r}{ }^{\prime}$ from the two friction sleeves for the load test which was conducted following full reconsolidation in borehole G. Shearing during the load test was at a rate of about $140 \mathrm{~mm} / \mathrm{min}$. The final set of data shown on Fig. 18 are the $\tau / \sigma_{r}{ }^{\prime}$ data calculated from the stresses measured by the IMP during extraction from borehole $G$ at a rate of about $1300 \mathrm{~mm} / \mathrm{min}$.
It is clear from the more extensive data we gathered at Madingley that in the Gault Clay there is no discernible rate effect on the friction angle which is mobilized on the IMP shaft.

The limited data obtained from the IMP at Canons Park appear to verify Bond \& Jardine's conclusion that the radial stresses acting on the

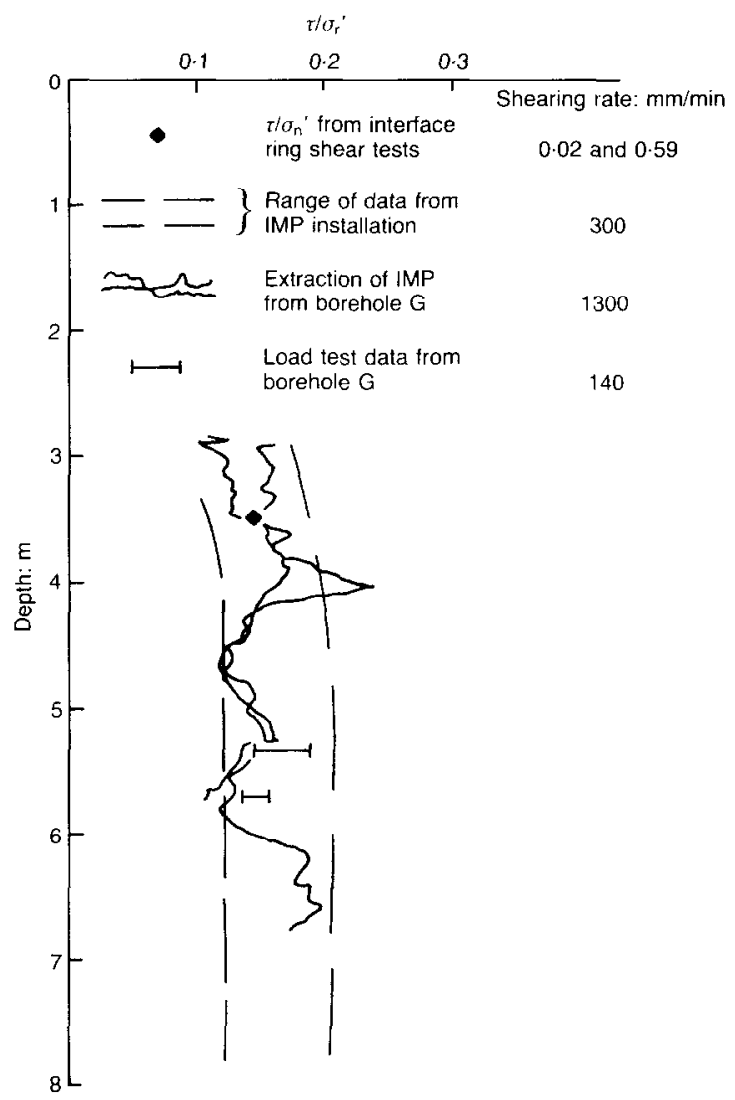

Fig. 18. Summary of $\tau / \sigma_{r}^{\prime}$ data from Madingley 
pile vary with distance from the tip. However, the data are slightly anomalous since although the radial effective stress for the upper set of transducers is significantly lower than for the lower set, the measurements of shaft friction are similar. In general, we found that the interpretation of such features from data obtained from Canons Park was complicated by the stratified nature of the soil at this site, which results in a sudden increase in the strength and stiffness of the soil at about $4 \mathrm{~m}$ depth, and it was for this reason that the majority of the IMP research was conducted in the more uniform Gault Clay at Madingley.

The scatter of data in Fig. 5 conceals some interesting features relating to the variation of stress measurements with distance from the pile tip. Fig. 19 shows the measurements of total radial stress made in four of the IMP boreholes at Madingley. Boreholes $\mathrm{E}$ and $\mathrm{F}$ were conducted in September 1985, and boreholes $G$ and $H$ in December. For the earlier boreholes there is a reduction in the total radial stress of around 100 $200 \mathrm{kPa}$ between the measurements made at a given depth by the lower and upper pairs of transducers. The data obtained from boreholes $G$ and $\mathrm{H}$ are of much better quality, and while the measurements of $\sigma_{\mathrm{r}}$ on the lower transducers were very similar to those from boreholes $E$ and $F$, the values measured by the upper transducers are much higher than in the earlier boreholes giving

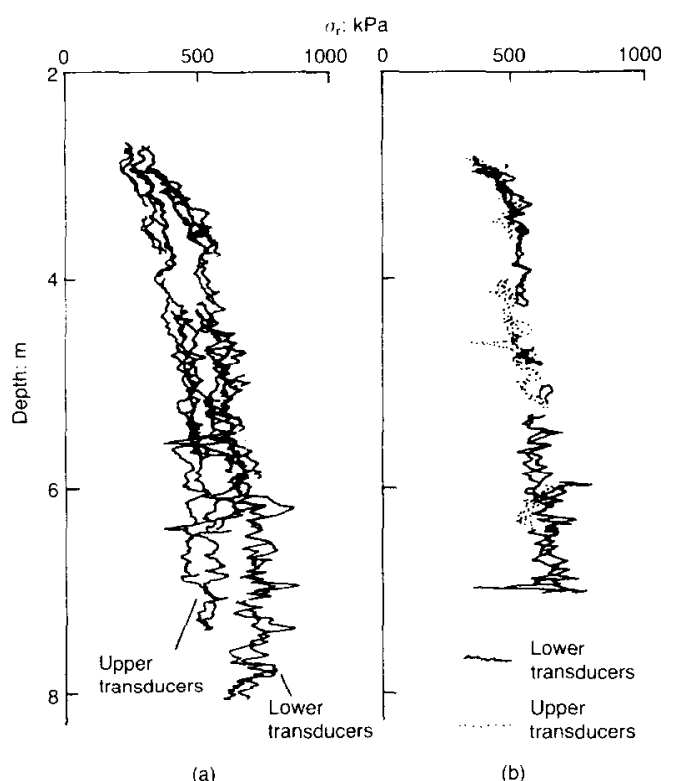

Fig. 19. IMP measurements of total radial stress during installation at Madingley: (a) boreholes $E$ and F; (b) boreholes $G$ and $H$ better agreement between the two sets of transducers. As outlined in the Paper, it is believed that the improvement in the quality of the data resulted from taking greater care in the assembly of the IMP, avoiding the distortion of the pile shaft which had been caused previously by overtightening of the connecting screws between each section. The resulting protuberances on the IMP shaft are thought to have caused relief of the total radial stresses acting on the shaft further up the pile. The fabrication tolerances of model piles may therefore influence the stresses measured upon them.

The data shown in Fig. 5 indicate that although differences were seen in the total stresses measured by the two sets of transducers, there does not appear to be any consistent difference in the measurements of $\sigma_{\mathrm{r}}{ }^{\prime}$. Reconsolidation was investigated in two boreholes at Madingley, data from one of which are presented in Fig. 7. In both cases the value of $\sigma_{r}^{\prime}$ for the two transducer sets after reconsolidation was identical. Although the IMP is a much shorter instrument than Bond \& Jardine's pile, the data presented in Fig. 15 indicate that a large decrease in $\sigma_{r}{ }^{\prime}$ should be observable along the length of the IMP shaft. The measurements from the Gault Clay at Madingley show no detectable differences between stresses measured at opposite ends of the shaft, and are therefore in sharp contrast to Bond \& Jardine's data, a point which requires further investigation.

\section{ACKNOWLEDGEMENTS}

The Authors would like to thank the Building Research Establishment for access to, and information about the Canons Park site.

\section{REFERENCES}

Bond, A. J. (1989). Behaviour of displacement piles in overconsolidated clays. PhD thesis, University of London.

Bond, A. J. \& Jardine, R. J. (1989). Instruments for measuring the effective stresses acting on a pile jacked into overconsolidated clay. Proc. Conf. on Geotech. Instrumentation in Civ. Engng Projects, Nottingham, $583-605$.

Jardine, R. J. \& Bond, A. J. (1989). Behaviour of displacement piles in a heavily overconsolidated clay. Proc. 12th Int. Conf. Soil Mech. \& Fndn Engng, Rio de Janeiro, 2, 1147-1151.

Jardine, R. J. \& Lemos, L. J. L. (1989). Discussion, Session 15, Static and dynamic testing of piles. Proc. 12th Int. Conf. Soil Mech. \& Fndn Engng, Rio de Janeiro, 2.

Lemos, L. J. L. (1986). The effect of rate on residual strength of soil. PhD thesis, University of London.

Tika, T. (1989). The effect of fast shearing on the residual strength of soils. PhD thesis, University of London. 